\title{
Contribuições da perspectiva crítica de base histórico-cultural para a produção científica em psicologia educacional
}

\author{
Laísy de Lima Nunes \\ Simone Salviano Alves' \\ Jaqueline Vilar Ramalho' \\ Fabíola de Sousa Braz Aquino
}

\section{Resumo}

Com ênfase na importância do monitoramento da produção científica, podendo o mesmo indicar qualidade da e rumos tomados pela produção do saber, o presente estudo visa a mapear as produções no âmbito da psicologia escolar educacional e, mais especificamente, nos artigos científicos que apresentem uma perspectiva crítica nessa área. Para tanto, foi realizada uma busca bibliográfica das versões on-line, publicadas entre 2007 e 2011, disponíveis na página da revista Psicologia Escolar e Educacional, publicação semestral da Associação Brasileira de Psicologia Escolar e Educacional (ABRAPEE). Ao todo, foram analisados 134 artigos. Os resultados apontaram que 17 artigos $(12,69 \%)$ foram classificados na perspectiva crítica. Cada estudo trata de importantes aspectos da psicologia escolar educacional, tendo como foco o papel do psicólogo na escola, a formação docente e a postura crítica dos agentes escolares. Todos os artigos selecionados fundamentam-se na teoria histórico-cultural, uma das abordagens críticas da psicologia resgatadas para a compreensão dos fenômenos educacionais, aqui considerados essencialmente psicossociais. Entende-se que esse levantamento representa um instrumento de fundamentação e de questionamento na formação acadêmica (graduação e pós-graduação) de alunos de psicologia, da área de educação e de áreas afıns, e propicia um maior aprofundamento acerca de como vem se configurando a psicologia escolar educacional contemporânea e dos impactos nas práticas profissionais orientadas por uma perspectiva crítica.

\section{Palavras-chave}

I- Universidade Federal da Paraíba,

Psicologia escolar educacional - Produção científica - Mapeamento Perspectiva crítica. 


\title{
Contributions of cultural-historical studies with a critical perspective to scientific production in educational psychology
}

\author{
Laísy de Lima Nunes' \\ Simone Salviano Alves \\ Jaqueline Vilar Ramalho' \\ Fabíola de Sousa Braz Aquino'
}

I- Universidade Federal da Paraíba, João Pessoa, PB, Brasil Contacts: la.laisy@hotmail.com; simone.psico@bol.com.br; jaqvilar@gmail.com; fabiolabrazaquino@gmail.com

\section{Abstract}

The present study seeks to map the productions in the scope of educational and school psychology and, more specifically, in the scientific articles that show a critical perspective in this area. This is done by emphasizing the importance of monitoring scientific production and its possibility of indicating the quality and directions taken by the production of knowledge. In order to achieve this, we have conducted a bibliographical search of the online versions published between 2007 and 2011, available in the journal Psicologia Escolar e Educacional (Educational and School Psychology), which is a biannual publication of Associação Brasileira de Psicologia Escolar e Educacional (ABRAPEE - Brazilian Association of Educational and School Psychology). Overall, 134 articles were analyzed. The results indicate that 17 articles (12.69\%) were classified in the critical perspective. Each study discusses important aspects of educational and school psychology, focusing on the role of school psychologists, teacher education, and the critical stance of school agents. All the articles selected were based on the cultural-historical theory, one of the critical approaches of psychology used to help understand educational phenomena, which are considered in this study as essentially psychosocial. This survey can be seen as a platform to evaluate the academic undergraduate and graduate background of psychology students in the field of education and similar areas, and it provides a deeper view on how contemporary educational and school psychology has been configured and its impact on professional practices guided by a critical perspective.

\section{Keywords}

Educational and school psychology - Scientific production Mapping - Critical poerspective. 


\section{Introdução}

Esse trabalho é produto de debates e reflexões sobre as interfaces da psicologia social com o campo educacional, por se entender a importância da relação entre esses campos de conhecimento para a prática profissional do(a) psicólogo(a) e, fundamentalmente, pelo valor atribuído às interações sociais como unidade de análise possível entre as referidas áreas (AROCHO, 2009, 2010; OVEJERO, 1996). Defende-se que estudar as relações entre esses campos da psicologia e conhecer os principais referenciais teóricos que orientam uma área permite entender e atuar profissionalmente de forma consciente e crítica nos contextos nos quais ocorre a atividade do(a) psicólogo(a).

$\mathrm{Na}$ compreensão de Ovejero (1996), nos últimos anos, assistiu-se a uma progressiva aproximação entre a psicologia social e a psicologia educacional, com destaque para o enfoque psicossocial como necessário e imprescindível na educação. Segundo afirma o autor, os fenômenos educacionais são essencialmente psicossociais, dado que compartilham duas classes: interpessoais (interação professor-aluno, aluno-aluno, pais e filhos) e grupais (tipo de grupo e de coesão do grupo-classe ou do grupo familiar). 0 autor enfatiza que, para abordar adequadamente toda a complexa problemática da educação atual, é imprescindível a adoção de uma perspectiva abertamente crítica e emancipatória.

Em relação a essa questão, Ovejero (1993, 1996) propõe a necessidade de um enfoque psicossocial, que leve em conta os aspectos psicológicos e sociais de um fenômeno que considera claramente psicossocial, qual seja, o fracasso escolar. Nessa linha, o fracasso escolar seria um fenômeno social e educacional, que reflete as relações entre indivíduo e sociedade. Em seu texto "Psicología social de la educación”, Ovejero (1996), ao apresentar o enfoque psicossocial para explorar as relações entre psicologia social e educacional, além de enfatizar a interação social como ponto de interseção entre essas duas áreas, recorre a Vygotsky como autor que embasa a referida proposta de análise.

Mais recentemente, Arrocho (2010) recorre ao modelo histórico-cultural para discutir as relações entre a psicologia social e a educação, desenvolvendo articulações entre esses dois campos de conhecimento. A partir da leitura e dos debates em torno dos textos de Ovejero (1993, 1996) e Arrocho (2009, 2010), buscou-se investigar a presença, na produção científica brasileira, da perspectiva crítica na área escolar e educacional.

Em consonância com pesquisadores brasileiros (MEIRA, 2003; SOUSA; SILVA, 2009; MALUF, 2010; MARTINEZ, 2010; NOVAES, 2010; FACCI; EIDT, 2011), observou-se, na literatura internacional, a recorrência à leitura e análise das questões educacionais a partir do modelo histórico-cultural inaugurado por Vygotsky (1932/1996; 1984/2007). Na literatura acima referida, o encontro da educação com a psicologia é atravessado por uma leitura histórico-cultural. Os pressupostos desse modelo põem em relevo a noção de sujeito constituído histórica e culturalmente, com destaque para os processos de formação do indivíduo a partir da rede social em que se insere. Partindo desse modelo, compreende-se que os processos de ensino e aprendizagem, que caracterizam as formas de socialização e viabilizam a apropriação de ferramentas culturais pelo homem, estão imbricados na formação da consciência e da subjetividade (AROCHO, 2009, 2010; OLIVEIRA; MARINHOARAÚJO, 2009).

No âmbito da psicologia escolar e educacional, Maria Helena de Souza Patto, na década de 1980, deflagrou uma crítica contundente ao enfoque clínico de atuação dentro das escolas, crítica essa que denunciava o modelo hegemônico na psicologia e defendia uma compreensão do fracasso escolar como fenômeno de múltiplas dimensões. Sustentava ainda que o trabalho do psicólogo escolar deveria "contribuir para a elucidação de processos 
que se dão na vida diária escolar, em suas relações com as dimensões econômica, política e cultural da sociedade brasileira" (PATTO, 1997, p. 467). Em suas elaborações, já pode ser encontrada uma crítica ao fazer psicológico na escola que, segundo ressalta, não percebia que "o que parece natural é social e o que parece a-histórico é histórico” (PATTO, 1997, p. 464). A crítica apresentada à comunidade científica por Patto (1997) influencia leituras e críticas mais contemporâneas, como as elaboradas por Meira (2003, 2012), Guzzo (2011), Facci e Eidt (2011), entre outros(as).

Na esteira desse debate, Meira (2003) defende a necessidade de uma concepção crítica que oriente o trabalho dos psicólogos educacionais e que traduza a compreensão de que "a relação entre o homem e a sociedade é de mediação recíproca, o que significa que os fenômenos psicológicos só podem ser devidamente compreendidos em seu caráter fundamentalmente histórico e social" (MEIRA, 2003, p. 19). Essa autora, fundamentada em parte nas críticas realizadas por Patto e nas proposições marxistas, compreende o homem como um ser essencialmente social, constituído nas e pelas condições e interações sociais.

Articulada ao âmbito educacional, Meira (2003, 2012) defende a escola como instituição socializadora das formas mais desenvolvidas do conhecimento humano e o psicólogo como mediador, comprometido ética e politicamente com as necessidades sociais. Cabe a ele refletir sobre seu papel dentro da escola, entendendo a educação como uma atividade que tem como meta a transformação social.

Arocho (2010) afirma que há um consenso entre os pesquisadores que adotam essa perspectiva crítica em relação à ideia de que a realidade e o conhecimento dela são construídos socialmente e que a educação é uma condição necessária para o desenvolvimento tipicamente humano. Essa interface entre psicologia e educação vem sendo construída gradativamente, a partir de questionamentos sobre a naturalização do desenvolvimento e sobre a descontextualização e fragmentação do indivíduo (OLIVEIRA; MARINHO-ARAÚJO, 2009). Corroborando essa afırmação, MarinhoAraújo (2010) defende que a relação entre a psicologia e a educação

(...) vem se estreitando, com teorias, pesquisas e formas de intervenção profissional que influenciam as duas áreas. Os diálogos e debates têm avançado por meio de novos paradigmas e prismas, que direcionam e redefinem formas mais dialéticas para a compreensão do desenvolvimento psicológico humano e da construção do conhecimento, quando ocorrem nos espaços educacionais. (p. 20).

Contudo, Marinho-Araújo (2010) afirma que vários desafios ainda se colocam, atualmente, diante da consolidação do perfil profissional do psicólogo atuante nos meios educacionais. Como outros autores (MALUF, 2010; CRUCES, 2009; GUZZO; MEZZALIRA, 2011; GUZZO; MEZZALIRA; MOREIRA; TIZZEI; SILVA NETO, 2010; MARINHO-ARAÚJO, 2010; MARTINEZ, 2010; MEDEIROS; BRAZ AQUINO, 2011), questiona-se de que forma a psicologia escolar e educacional tem comparecido nessa discussão e se as atividades do psicólogo nos meios educacionais têm se pautado por uma orientação crítica, de base histórico-cultural.

Diante do exposto, o presente estudo buscou mapear produções que tivessem como foco a psicologia escolar e educacional abordada de forma crítica, influenciada pelo modelo histórico-cultural de Vygotsky, entendido enquanto uma das abordagens críticas dessa área. Isso porque esse modelo tem fundamentado, com frequência, pesquisas da área educacional que exploram as articulações entre a educação escolar e as interações sociais mais amplas (MEIRA, 2003, 2012; FACCI; EIDT, 2011; OLIVEIRA; MARINHO-ARAÚJO, 2009). Nesses estudos, a relação entre essa teoria e o contexto educacional dá-se pelas possibilidades de leitura da realidade educacional, utilizando 
conceitos como interação social, cultura, escola, enquanto um campo de relações e de transmissão dos conhecimentos historicamente construídos, mediação, e o papel da atividade coletiva no desenvolvimento humano (MEIRA, 2012).

Diante disso, monitorar a produção científica pode funcionar como um crivo que indique a qualidade e os rumos tomados pela produção do saber. Ter conhecimento dessas produções contribui para a identificação dos temas que estão sendo discutidos, dos avanços e das lacunas que ainda precisam ser investigadas, com vistas a fundamentar práticas nos contextos educacionais e a promover avanços na área (OLIVEIRA; CANTALICE; JOLY; SANTOS, 2006; SOUZA FILHO; BELO; GOUVEIA, 2006).

Desse modo, faz-se necessária a elaboração de trabalhos que organizem o corpo de conhecimento científico produzido, tendo em vista que seus resultados serão úteis para pesquisas futuras e para a elaboração de propostas de intervenção em diversos campos de atuação (OLIVEIRA; SANTOS; NORONHA; BORUCHOVITCH; CUNHA; BARDAGI; DOMINGUES, 2007; COSMO; URT, 2009).

Agências de fomento à pesquisa, em diversos países, têm investido na realização de avaliações da produção, com destaque para aquelas publicações em periódicos científicos reconhecidos e conceituados. No cenário nacional, entretanto, ainda há uma carência nesse campo que conceitua e caracteriza a publicação psicológica nacional (OLIVEIRA; CANTALICE; JOLY; SANTOS, 2006). Consoante a essa ideia, Witter (2008) indica que as investigações que visam a avaliar outras pesquisas não são comuns no Brasil, mas começam a ser desenvolvidas. A autora destaca a importância dessas produções ao fomentar subsídios para a produção do conhecimento, definição de políticas de pesquisa e pós-graduação.

Com o objetivo de contribuir para que as investigações científicas assumam uma postura mais rigorosa e informativa e possam oferecer uma melhor base para os programas educativos e as políticas decisórias, Bariani, Buin, Barros e Escher (2004) realizaram uma análise dos objetivos, métodos e enfoques utilizados em pesquisas. Revisaram aquelas realizadas nos cinco anos anteriores ao trabalho e que relatassem estudos sobre a psicologia escolar e educacional no ensino superior.

A partir dessa revisão, as autoras concluíram que: a maioria dos objetivos que se propuseram os documentos refere-se ao conhecimento do perfil de estudantes universitários; predominaram estudos de caráter descritivo; quanto aos instrumentos de coleta de dados, prevaleceu a utilização de instrumento único, composto por material impresso; o procedimento de análise mais utilizado foi o quantitativo; os informantes foram principalmente estudantes universitários; e os trabalhos analisados foram desenvolvidos tendo uma sólida base teórica.

Cosmo e Urt (2009), reconhecendo a importância da análise da produção científica, realizaram uma pesquisa que visou a identificar a presença do conhecimento psicológico nas produções científicas sobre a escola. Nessa mesma vertente, Oliveira e colaboradores (2007) pesquisaram acerca da produção científica sobre avaliação psicológica no contexto escolar. Considerando as colocações acima, evidencia-se a importância de pesquisas que analisem a produção bibliográfica que vem sendo construída nessa área do conhecimento.

Pontua-se que ainda há muito para ser conquistado nessa esfera, com o intuito de aproximar teoria e prática. Em termos históricos, o crescimento da área escolar e educacional na psicologia não ocorreu de forma paralela à criação de elementos teóricos e metodológicos que fundamentem e consolidem práticas transformadoras e emancipatórias. Diversas críticas são tecidas buscando mostrar que a área educacional tem ações limitadas, por vezes fundamentadas na patologização dos problemas escolares, com uma visão adaptacionista e que culpabiliza o aluno; ao invés de contribuir para a construção de uma educação democrática, o que, de fato, é o seu papel. Compete à 
psicologia escolar e educacional contribuir para que a escola realize satisfatoriamente seu papel de socialização do saber, de favorecimento de processos de humanização e de promoção do pensamento crítico (MEIRA; ANTUNES, 2003).

Para colaborar com essa construção, este trabalho visa a mapear as produções no âmbito da psicologia escolar e educacional e, mais especificamente, nos estudos que apresentem uma perspectiva crítica nessa área, tendo em vista, como afirmam Meira e Antunes (2003), que esse pensamento crítico pode contribuir para "a adoção de um compromisso social com a cidadania” (p. 11). Além disso, apesar desse movimento crítico ter surgido na década de 1980, com os estudos Patto, muito ainda precisa ser feito para que seus pressupostos se concretizem e, nesse sentido, a produção científica sobre esse tema é um elemento essencial para a elaboração de novas práticas. Dessa forma, explicitam-se: quais têm sido os principais temas abordados nas pesquisas; os referenciais teóricos adotados pelos pesquisadores; os tipos de pesquisas realizadas; os participantes e os resultados encontrados nos artigos da revista Psicologia Escolar e Educacional.

Entende-se como crítica, em concordância com Meira (2003), uma concepção ou teoria que “(...) apreende a totalidade do concreto em suas múltiplas determinações e compreende a sociedade como um movimento de vir-a-ser" (p. 17). Baseada nesse conceito, a autora recorre a concepções críticas de educação e psicologia como uma possibilidade de fundamentação mais consistente para a psicologia escolar e educacional. Sousa e Silva (2009) afirmam que um dos principais critérios para a defınição de um trabalho crítico na área em foco é a explicitação de compromisso com a psicologia escolar e a educação, no que diz respeito especialmente aos pressupostos teóricos e a sua relação com a prática.

Souza e Checchia (2003) também apontam alguns elementos imprescindíveis para a formação e a atuação baseada na perspectiva crítica, tais como a ruptura epistemológica relativa à visão adaptativa que, por vezes, fundamenta algumas práticas psicológicas. Diante disso, a reflexão crítica se constitui como necessária a toda a sociedade e primordialmente àqueles que atuam no âmbito educacional. Pensar a psicologia educacional em uma perspectiva crítica significa analisar a atuação, as concepções e práticas dos psicólogos nessa área, valorizar o contexto social em que o sujeito está inserido e considerar a realidade vivida pelo sujeito para poder compreender sua realidade educacional (MEIRA, 2003; FACCI; EIDT, 2011).

Para alcançar os objetivos propostos, a presente pesquisa analisou, particularmente, os artigos científicos publicados na revista Psicologia Escolar e Educacional, no período de 2007 a 2011. Considerou-se relevante iniciar o levantamento a partir desse período, tendo em vista que, no ano de 2004, foi elaborado o Parecer no CNE/CES 0062/2004, e este originou a Resolução CNE/CES no 8 de 7 de maio 2004, que instituiu as novas Diretrizes Curriculares Nacionais para os cursos de psicologia no Brasil (BRASIL, 2004). Tais diretrizes estabelecem a construção de princípios e fundamentos norteadores da formação do psicólogo, forjadas a partir de um amplo debate entre os profissionais da área. 0 processo histórico de elaboração dessas diretrizes e os posicionamentos e desdobramentos em relação a esse documento têm sido alvo de debates e publicações de diversos autores na área educacional (GUZZO; MEZZALIRA, 2011; MALUF, 2010; CRUCES, 2009). Tal documento guarda a expectativa de possibilitar uma formação abrangente, que desenvolva habilidades e competências que respondam às demandas dos diversos contextos de atuação desse profissional. Nesse sentido, evidencia-se que

(...) a Psicologia Escolar poderá beneficiar-se quanto à ampliação das concepções acerca da formação desejada para uma atuação competente e coadunada às demandas atuais, pois o momento histórico contemporâneo está propício às mudanças 
que já vêm ocorrendo na área. (MARINHOARAÚJO, 2010, p. 26)

A revista semestral da Associação Brasileira de Psicologia Escolar e Educacional (ABRAPEE) foi escolhida por ser o periódico científico de uma associação de abrangência nacional da área da psicologia educacional, que busca propagar o conhecimento de práticas e pesquisas originais e atuais nesse campo. Seu propósito é a publicação de manuscritos referentes à atuação, formação e história da psicologia no âmbito educacional, textos de reflexão crítica e relatos de pesquisas. Vale destacar que outras publicações também apresentam trabalhos na perspectiva escolar crítica. No entanto, esse periódico foi escolhido por ser específico da área da psicologia escolar e educacional e por sua representatividade nas produções desse campo.

\section{Método}

Como se disse antes, inicialmente, foram escolhidas para a análise as publicações de Psicologia Escolar e Educacional, revista da Associação Brasileira de Psicologia Escolar e Educacional (ABRAPEE). Em seguida, realizou-se uma busca bibliográfica das versões on-line disponíveis na página desse periódico, cobrindo o período 2007-2011. Analisaram-se apenas as edições regulares da revista, excluindo-se assim uma edição especial do ano de 2007 e o número dois do volume 12 (2008), que, na época da coleta de dados, não estava acessível na rede. ${ }^{1}$

Cada exemplar da revista apresentava quatro modalidades de publicações: artigos; resenhas; histórias; e, por fim, sugestões práticas. Tendo em vista as necessidades desta pesquisa, optou-se por analisar apenas os materiais que se encontravam na modalidade artigo. Cada artigo foi lido na íntegra por duas das pesquisadoras,

1 - Atualmente, a edição especial (2007) e 0 número dois do volume 12 (2008) podem ser localizadas nos respectivos endereços: http://www.scielo.br/scielo.php?script=sci_issuetoc \&pid=1413855720080002\&lng=pt\&nrm=iso e http://abrapee.psc.br/Especial.pdf que realizaram os levantamentos de forma independente, preenchendo a ficha de análise, a qual foi desenvolvida a partir do modelo original de Bariani e colaboradoras (2004) e adaptada de acordo com os fins aqui propostos. Posteriormente, os resultados encontrados foram discutidos em reuniões com o grupo de pesquisadoras, garantindo-se consenso entre as juizas.

Por fım, foi realizada uma análise, em termos quantitativos e qualitativos, dos artigos que contemplavam o critério preestabelecido. Ressalta-se que o critério utilizado foi que os artigos apresentassem discussões críticas sobre a atuação e/ou formação do psicólogo escolar, pautadas essencialmente na psicologia histórico-cultural, entendida como uma das abordagens críticas da psicologia que propõe uma ruptura com o modelo clínico de atuação. Os resultados foram organizados e serão apresentados e discutidos, atendendo os objetivos deste trabalho.

\section{Resultados e discussão}

Ao todo, foram analisados nove números da revista Psicologia Escolar e Educacional, contabilizando o total de 134 artigos. Dentre todos os artigos, 17 (12,69\%) foram classificados no critério estabelecido inicialmente de psicologia escolar e educacional numa perspectiva crítica, ou seja, apresentam uma discussão que rompe com a lógica patologizante dos problemas educacionais e propõe uma prática emancipatória, tendo o psicólogo como agente dessa mudança. Nesses artigos, foram feitas análises mais minuciosas, considerando os seguintes critérios: data de publicação; autoria e filiação institucional; objeto de estudo; enfoques teórico e metodológico; e conclusões dos estudos.

\section{Data da publicação}

A análise dos artigos indicou que, apesar da pesquisa abranger os anos de 2007 a 2011, a perspectiva crítica esteve mais presente 
nos documentos de 2010 e 2011, tendo maior concentração (cinco artigos) no primeiro número publicado no ano de 2011. Esses dados sugerem o crescimento de discussões críticas nas produções desse periódico ao longo dos anos. Essa tendência pode ser constatada também nas formas de atuação dos psicólogos e na reestruturação das grades curriculares dos cursos de psicologia das universidades brasileiras. Mesmo sendo uma discussão que remete à década de 1980, as transformações ainda estão ocorrendo lentamente. Todavia, estão evoluindo e conquistando gradativamente mais espaço para debates e atuações (MEIRA, 2003, 2012; SOUZA; CHECCHIA, 2003), embora as mudanças em torno dessa questão ainda se mostrem, na prática, pouco perceptíveis.

Outro aspecto que pode estar associado ao aumento da produção em uma perspectiva crítica a partir de 2010 é o conjunto de mudanças na política editorial da revista Psicologia Escolar e Educacional que foi implantado no segundo semestre de 2009 e aprimorado nos anos seguintes. Nesse período, o referido periódico teve seu pedido de inserção no SCIELO atendido e, em decorrência disso, artigos teóricos começaram a ser aceitos. Fez-se necessário, então, acurar cada vez mais todos os procedimentos editoriais e de avaliação dos manuscritos para atender aos critérios de excelência dessa base de dados.

\section{Autoria e filiação institucional}

Entre os 17 artigos classificados, constatou-se que a maioria $(94,12 \%)$ possui autoria coletiva. Desse total, apenas dois artigos (11,76\%) apresentam co-autores do sexo masculino, o que reafirma a tradição da psicologia escolar como uma área de conhecimento de domínio predominantemente feminino (OLIVEIRA et al, 2006).

Em 29,41\% dos artigos, todos os autores, na época da publicação, tinham vínculos com universidades da região sul (Paraná e Santa Catarina); 23,53\% tinham seus autores vinculados a universidades da região sudeste (São Paulo e Minas Gerais); em 17,65\% dos artigos, os autores eram vinculados a universidades do Distrito Federal; 11,76\% eram de Rondônia, único estado da região norte que apareceu nessas publicações; e apenas em um artigo (5,88\%), os autores eram exclusivamente da região nordeste. Dois artigos tinham autores que eram vinculados a instituições de estados diferentes, sendo o primeiro escrito por uma autora do Maranhão (nordeste) e outra do Distrito Federal (DF), e o segundo por autoras de Rondônia e de São Paulo (norte e sudeste). Nota-se, através dos vínculos empregatícios declarados, um engajamento dos autores com a vida acadêmica e com a área de conhecimento em questão.

Diante desses dados, observou-se que essas pesquisas estão mais concentradas nas regiões sul e sudeste do país, o que corrobora a ideia de um predomínio histórico dessas regiões como mais desenvolvidas no âmbito da ciência e da produção de conhecimento. Esses resultados são congruentes com outros encontrados em trabalhos que analisaram a produção na área da psicologia escolar e educacional, como o de Oliveira e colaboradores (2006), por exemplo. Isso também se justifica pela maior concentração dos cursos de psicologia do país, tanto de graduação como de pós-graduação, nessas localidades.

\section{Abordagem teórica}

No tocante à fundamentação teórica, utilizou-se como critério para a análise dos artigos que eles apresentassem uma discussão crítica pautada no uso da teoria históricocultural, entendendo ser essa uma das principais abordagens que subsidiam leituras críticas no campo da psicologia escolar. Desse modo, todos os artigos classificados destacam a importância dessa teoria, por considerar os aspectos sociais, culturais e relacionais existentes na instituição escolar. Nessa teoria, o ser humano é entendido como formado a partir das relações sociais, e tanto a escola quanto os 
processos educacionais de maneira geral têm destaque especial (ALMEIDA; ALVES; NEVES; SILVA; PEDROZA, 2007; TONDIN; DEDONATTI; BONAMIGO, 2010; WANDERER; PEDROZA, 2010; BRAY; LEONARDO, 2011; LESSA; FACCI, 2011;). Os autores do presente estudo, pautados nessa concepção, defendem que os agentes escolares têm a possibilidade de romper com o paradigma tradicional que culpabiliza o aluno pelo fracasso e queixas escolares, e repensar suas práticas. Os estudos aqui analisados consideram o sujeito como ser social e, portanto, inserido em um contexto que o influencia e é influenciado por ele. Esses dados corroboram os argumentos de Ovejero (1993, 1996), quando aponta a abordagem histórico-cultural de base vygotskiana como uma das mais coerentes para analisar a interface psicologia social e educação.

Os proponentes deste estudo concordam com os autores que defendem que essa teoria ajuda a compreender a importância de vários processos na dinâmica escolar que afetam o desenvolvimento das crianças. A teoria histórico-cultural auxilia o processo de reflexão crítica sobre a realidade escolar e fundamenta o compromisso necessário à atuação nesse âmbito. (CARVALHO; MARINHO-ARAÚJO, 2009; SANT'ANA; EUZÉBIOS FILHO; LACERDA JUNIOR; GUZZO, 2009).

Foi destaque nesses trabalhos o uso dos principais teóricos da corrente históricocultural: Vygotsky, Leontiev e Luria. Novas contribuições da literatura atual na área, autores como Patto, Marinho-Araújo, Guzzo, Almeida, Meira, entre outros, também foram citados por estabelecerem uma produtiva articulação crítica entre os conceitos da teoria histórico-cultural e o contexto vigente no sistema escolar brasileiro, considerando aspectos éticos, sociais, políticos e institucionais (LONGAREZI; ALVES, 2009; BRASILEIRO; SOUZA, 2010; SCHLINDWEIN, 2010; SOARES; MARINHO-ARAÚJO, 2010; FONTES; LIMA, 2011; PIOTTO; ALVES, 2011).

Dessa forma, todos os artigos defendem que a escola e, consequentemente, todos os agentes escolares, devem assumir um compromisso com a transformação, indo além da transmissão de conhecimentos científicos, devendo, para isso, priorizar uma formação voltada para a cidadania, através da educação e da reflexão crítica. (BRAY; LEONARDO, 2011).

\section{Tipos de pesquisa e participantes}

Entre os 17 artigos analisados, 13 expõem estudos de campo, os quais apresentam como sujeitos das pesquisas: psicólogos escolares (FACCI; TESSARO; LEAL; SILVA; ROMA, 2007; LONGAREZI; ALVES, 2009; WANDERER; PEDROZA, 2010; TADA; SÁPIA; LIMA, 2010; GASPAR; COSTA, 2011; LESSA; FACCI, 2011; SOUZA; RIBEIRO; SILVA, 2011); estudantes do ensino fundamental, médio e/ou superior (SANT'ANA; EUZÉBIOS FILHO; LACERDA JUNIOR; GUZZO, 2009; FONTES; LIMA, 2011; PIOTTO; ALVES, 2011); grupos de professores (ALMEIDA; ALVES; NEVES; SILVA; PEDROZA, 2007; BRAY; LEONARD0, 2011); e secretários municipais de educação (TONDIN; DEDONATTI; BONAMIGO, 2010).

Os outros quatro artigos são revisões bibliográficas (BRASILEIRO; SOUZA, 2010; CARVALHO; MARINHO-ARAÚJO, 2009; SCHLINDWEIN, 2010; SOARES; MARINHOARAÚJO, 2010), e discutem a formação de docentes e de psicólogos no Brasil, bem como as concepções da psicologia escolar crítica.

\section{Conclusões dos estudos}

Todos os estudos tratam de importantes aspectos da psicologia escolar e educacional. A partir de fundamentações elaboradas com base nos pressupostos histórico-culturais, rigor metodológico e procedimentos de análises, chegam a conclusões que podem contribuir para a reflexão sobre as práticas nessa área e subsidiar novas atuações de caráter crítico e emancipatório.

Almeida, Alves, Neves, Silva e Pedroza (2007) analisam a visão de professores do 
ensino médio sobre a influência da psicologia em sua atuação. Elas defendem a relação entre pedagogia e psicologia, considerando ambas importantes. Veem a formação do professor a partir de uma perspectiva "inovadora”, na qual ele reflete sobre sua atuação e interação com os alunos. Longarezi e Alves (2009) abordaram a questão da formação continuada de professores, considerando a contribuição da psicologia escolar para a construção de um cenário social mais crítico e comprometido com políticas efetivas. Esse trabalho concentrou-se na elaboração, no desenvolvimento e na avaliação coletiva de um projeto pedagógico na escola.

Nesse sentido, em ambos os trabalhos, percebe-se que a psicologia pode contribuir significativamente para a mudança nos cenários educacionais. Tendo em vista que a atuação do psicólogo na escola pode colaborar para a formação continuada do professor, ela pode ajudar o desenvolvimento profissional e pessoal desse profissional, além de chamar a atenção dele para uma postura mais crítica e prático-reflexiva sobre seu próprio trabalho. Essas considerações justificam a classificação desses artigos nos critérios estabelecidos, por se considerar, tal como as autoras, que alguns conteúdos de psicologia são importantes não apenas para os psicólogos, mas também para os demais agentes educacionais, em especial, o professor, já que todos devem estar envolvidos na construção da cidadania.

Ainda sobre esse tema, Soares e Marinho-Araújo (2010) destacam a importância da mediação do psicólogo escolar para o desenvolvimento de competências dos educadores sociais. Elas abordam criticamente o modelo tradicional de atuação clínica dos psicólogos escolares, destacando a importância de intervenções com foco nas relações entre os agentes escolares, principalmente o apoio ao processo de ensino e aprendizagem. Dessa forma, os psicólogos escolares devem potencializar uma atuação que contribua para a otimização das relações sociais institucionais.

Schlindwein (2010), por sua vez, discutiu a relação entre teoria e prática no campo da psicologia da educação e suas implicações para a formação de educadores, através da revisão dos trabalhos apresentados nas reuniões anuais da Associação Nacional de Pós-Graduação e Pesquisa em Educação (ANPEd), especialmente no Grupo de Trabalho Psicologia da Educação (GT20), no período entre 1998 e 2009. Esse artigo também mostra que é preciso trazer as contribuições da psicologia para uma visão mais ampla, que permita compreender a escola e seus atores em todas as suas dimensões.

Nessa mesma linha de discussão, Wanderer e Pedroza (2010) tratam do psicólogo enquanto agente transformador e crítico que pode questionar relações de hierarquização, bem como trabalhar com os agentes escolares sobre as concepções históricas acerca da identidade da escola e as mudanças possíveis a partir da ação coletiva da comunidade. Para que isso se concretize, faz-se necessário romper com uma prática adaptativa que usa rotulações e implementar um modelo de formação de indivíduos crítica e politicamente conscientes.

Tondin, Dedonatti e Bonamigo (2010), buscando entender os elementos inovadores e pertinentes às discussões atuais na área de psicologia escolar e educacional, discutiram as concepções de psicologia escolar presentes em projetos de lei. Nesse artigo, conclui-se que a legislação abrange uma variedade de concepções teóricas e essas repercutem diretamente nas ações e nos resultados dos trabalhos dos psicólogos, divergindo de acordo com a atuação crítica de cada profissional e o contexto no qual ele está inserido.

Partindo das concepções vigentes de psicologia escolar e educacional, alguns artigos apresentaram temas relativos à formação e ao cenário atual de alguns contextos específicos. Brasileiro e Souza (2010) analisaram a formação de psicólogos diante das novas diretrizes de 2004 (BRASIL, 2004), no que se refere aos processos educativos na Amazônia. Eles ressaltam alguns avanços em uma perspectiva emancipatória, com pensamentos e ações questionadoras, perspectiva essa capaz de formar profissionais 
críticos, preocupados e conectados com as transformações na área educacional.

A pesquisa realizada por Carvalho e Marinho-Araújo (2009) trata da realidade da psicologia escolar no Maranhão. Por meio de um estudo bibliográfico sobre o tema, são levantadas reflexões sobre o histórico e as tendências atuais no âmbito da formação e atuação do psicólogo escolar nesse estado. As autoras mostram que, apesar das dificuldades de atuação nessa área, as possibilidades de mudanças e novas configurações estão crescendo e contribuindo para uma educação mais democrática.

A rede pública de ensino de Rondônia foi estudada por Tada, Sápia e Lima (2010), que mostram que a inserção do psicólogo nesse âmbito é recente e que a maioria deles atua de forma clínica nas escolas, por exemplo, realizando atendimentos individuais por tempo prolongado. Os autores criticam esse tipo de formação e atuação e sugerem uma prática pautada na teoria histórico-cultural.

Souza, Ribeiro e Silva (2011) investigaram a prática do psicólogo escolar na rede particular de ensino da cidade de Uberlândia (MG). Os resultados constataram que a inserção desse profissional no âmbito educacional privado reflete questões históricas da construção da psicologia escolar no Brasil. A atuação dos psicólogos, nesse contexto, também é pautada por visões tradicionais, resultantes de uma formação desarticulada dos avanços nessa área de conhecimento.

Outros temas pertinentes são apresentados nas publicações analisadas e levam à reflexão crítica sobre as possíveis formas de atuação do psicólogo. As concepções e práticas do psicólogo escolar sobre a afetividade na relação professor-aluno foram estudadas por Gaspar e Costa (2011). Esse estudo enfoca os aspectos preventivo, criativo e interdisciplinar que a atuação do psicólogo no âmbito escolar exige. Cabe ao profissional da área trabalhar com processos afetivos que envolvem os agentes escolares, possibilitando o desenvolvimento desses sujeitos. Para alcançar esse objetivo, é preciso romper com paradigmas tradicionais e ampliar a visão das possibilidades de atuação.

Facci, Tessaro, Leal, Silva e Roma (2007), Piotto e Alves (2011), Lessa e Facci (2011) e Bray e Leonardo (2011) realizaram estudos sobre o fracasso e/ou as queixas escolares, tendo por base a teoria histórico-cultural e produções recentes da psicologia escolar e educacional. Apesar das diferenças existentes entre os contextos e os participantes dessas quatro pesquisas, os autores chegaram a algumas conclusões comuns. Eles defendem que a escola representa uma influente instituição na formação do sujeito e que os agentes escolares devem estar aptos para educar para a cidadania. Essa literatura trata o fracasso escolar de forma mais ampla e considera os diversos agentes escolares, o que possibilita uma prática pautada em questões mais abrangentes e críticas.

Assim, faz-se necessário romper com uma visão tradicional, que afırma que o fracasso e/ou as queixas escolares estão diretamente relacionadas apenas aos alunos. A escola também tem um papel importante na produção do fracasso escolar e diversos aspectos da instituição precisam ser analisados e repensados.

Alguns autores procuram entender o papel do psicólogo escolar e a realidade da escola a partir da concepção dos alunos. Sant'Ana, Euzébios Filho, Lacerda Junior e Guzzo (2009), ao realizarem um estudo com estudantes do ensino fundamental, concluíram que, de maneira geral, diversas limitações foram encontradas na compreensão do papel do psicólogo no ambiente escolar. Diante disso, as autoras fazem uma crítica à visão predominante, a do modelo clínico de intervenção. Elas destacam o surgimento de atuações de caráter preventivo e comunitário e afirmam que isso precisa se consolidar na prática escolar.

Fontes e Lima (2011) realizaram uma pesquisa com alunos do ensino médio da rede pública estadual de Porto Velho (RO) sobre a escola e o processo de aprendizagem. Os resultados evidenciam uma escola que tem como foco apenas a transmissão do conteúdo, 
realizada por meio de aulas expositivas e descontextualizadas das necessidades dos alunos. A psicologia escolar e educacional numa visão crítica, como apresentada pelas autoras, enfatiza a importância de se compreender o ponto de vista de todos os atores escolares sobre o cotidiano escolar, em suas várias facetas. Considera-se que, a partir da formação contínua e adequada, os psicólogos encontram fundamentos reais para sustentar seus planejamentos e novas formas de atuação, preocupados com a dinâmica da instituição e com as concepções de todos os agentes envolvidos no processo educacional.

\section{Consideraçōes finais}

Esta pesquisa propôs mapear as publicações de Psicologia Escolar e Educacional, revista da Associação Brasileira de Psicologia Escolar e Educacional (ABRAPEE), no período de 2007 a 2011, com foco nos estudos que apresentassem discussões críticas sobre a psicologia escolar educacional, pautadas na psicologia histórico-cultural, compreendida aqui como uma das abordagens críticas da psicologia, que propõe uma ruptura com o modelo clínico de atuação. Inicialmente, pode-se observar que, quando se pretende realizar uma análise da produção científica em uma determinada área da psicologia, diversos aspectos devem ser considerados. Dentre eles, cabe destacar o acesso aos materiais a ser analisados. Por vezes, as bibliotecas institucionais não os disponibilizam, o que revela a importância das bases de dados on-line, tal como aquela utilizada nesta pesquisa, para o avanço da produção do conhecimento científico.

No que se refere especificamente à análise dos artigos, constatou-se que muitos apresentam questionamentos sobre e críticas ao sistema educacional em diferentes esferas. Todavia, foram analisados exclusivamente os trabalhos que discutiam a atuação do psicólogo escolar e educacional na perspectiva crítica, e concluiu-se que a quantidade de material classificado no critério estabelecido inicialmente de perspectiva crítica foi baixa em relação ao número total analisado. Porém, pode-se perceber, nos artigos que apresentaram tal perspectiva, um sólido embasamento na perspectiva histórico-cultural.

Ratificando essa ideia, Arocho (2009) explicita que os pressupostos histórico-culturais, especialmente as contribuições de Vygotsky, Luria e Leontiev, configuram novos entendimentos sobre a realidade, o conhecimento e o sujeito, sendo ponto de partida para a articulação entre a psicologia social e a psicologia escolar e educacional numa perspectiva crítica e psicossocial. A teoria histórico-cultural destaca que a atividade psíquica superior tem origem social e suas formas de expressão resultam das condições históricas e culturais de sua produção. Dessa forma, os processos de ensino-aprendizagem que ocorrem em contextos sociais, tais como a escola, viabilizam a apropriação das ferramentas culturais e promovem a formação de consciência e a constituição de subjetividade (VYGOTSKY, 2007; AROCHO, 2009; OLIVEIRA; MARINHOARAÚJO, 2009; OVEJERO, 1996).

Os autores desse estudo consideram que a teoria histórico-cultural, enquanto uma perspectiva da psicologia escolar e educacional crítica, fornece ferramentas teóricas e metodológicas que permitem ao psicólogo, em seu contexto de trabalho, atuar junto às demandas concretas, na perspectiva de adotar ações que expressem compromisso social com uma escola mais igualitária, mais justa e que, de fato, atende a sua função social. Defendem ainda que essa abordagem crítica fundamenta reflexões sobre práticas mais condizentes com a realidade social na qual cada profissional está inserido, na tentativa de promover mudanças que ajudem a traçar um caminho para uma atuação democrática e emancipatória. Nesse sentido, a revisão desses trabalhos configura-se como importante por ser mais um instrumento de fundamentação e de questionamento, tanto na formação acadêmica (graduação e pós-graduação) de 
alunos de psicologia e de áreas afıns, quanto na formação continuada de profissionais já inseridos no campo de trabalho.

Acrescenta-se que, na trajetória de construção e consolidação na área, foram apresentadas fortes críticas e reivindicações, entre os próprios pesquisadores desse campo, sobre a necessidade de uma reestruturação dos pressupostos teórico-metodológicos que orientavam a formação (inicial e continuada) e a prática do psicólogo nos meios educacionais (PATTO, 1997; MEIRA, 2003; GUZZO; MEZZALIRA; MOREIRA; TIZZEI; SILVA NETO, 2010; MALUF, 2010; NOVAES, 2010; GUZZO, 2011). Foi dessa inquietação que começou a ser observado o resgate da teoria históricocultural, pela alegação de que o indivíduo não pode ser explicado subtraindo-lhe a dimensão sociocultural e histórica e que a escola, enquanto célula social, expressa as contradições e movimentos do sistema político e educacional.
Por fim, considera-se importante mencionar que o levantamento aqui apresentado não permite capturar o movimento de efervescência e inquietação dos pesquisadores da área educacional, dentre outros aspectos, por ser a escola uma arena complexa, contraditória, que sofre a interferência necessária e profícua do plano sócio-histórico e político que a demarca. Assim, espera-se que a presente pesquisa possa contribuir para reflexões acerca do significado que tem revelar o que já foi pensado, produzido e sentido sobre uma determinada área do conhecimento, podendo, dessa forma, não só apontar caminhos percorridos, mas também sinalizar novas possibilidades de atuação, que respondam às demandas atuais do campo educativo. E, ainda, integrar um conjunto de estudos acerca do fenômeno em foco, identificando temas que carecem de evidências, auxiliando, de modo geral, na orientação de pesquisas futuras que possam continuar contribuindo com a produção do conhecimento.

\section{Referências}

ALMEIDA, Rúbia; ALVES, Cândida; NEVES, Gabriella; SILVA, Ludmila; PEDROZA, Regina. 0 professor de ensino médio e a psicologia em seu cotidiano escolar. Psicologia Escolar e Educacional, Maringá, v. 11, n. 1, p. 123-132, 2007.

AROCHO, Wanda C. Rodríguez. Hacia uma psicologia social crítica de la educación em América Latina. Universidad de Puerto Rico. 2009. Disponível em: <http://paideia.uprrp.edu/Articulos/Volumen\%205\%20Num.\%201\%20(enero\%20-\%20mayo\%20 2010)/Hacia\%20una\%20psicologia\%20social\%20critica\%20de\%20la\%20educacion\%20en\%20America\%20Latina-Wanda. pdf>. Acesso em: 15 maio 2012.

AROCHO, Wanda C. Rodríguez. El concepto de calidad educativa: uma mirada crítica desde el enfoque históricocultural. Actualidades Investigativas em Educación, San Pedro de Montes de Oca, Costa Rica, v. 10, n.1, p. 1-28, 2010.

BARIANI, Isabel Cristina D.; BUIN, Edimariz; BARROS, Raquel de Camargo; ESCHER, Carolina de Aragão. Psicologia escolar no ensino superior: análise da produção científica. Psicologia Escolar e Educacional, Maringá, v. 8, n. 1, p. 17-27, 2004.

BRASIL. Ministério da Educação. Parecer CNE/CES n. 62 de 19 de fevereiro de 2004. Diretrizes curriculares nacionais para os cursos de graduação em psicologia. Brasília: MEC. 2004.

BRASILEIRO, Tânia Suely A.; SOUZA, Marilene Proença R. Psicologia, diretrizes curriculares e processos educativos na Amazônia: um estudo da formação de psicólogos. Psicologia Escolar e Educacional, Maringá, v. 14, n.1, p. 105-120, 2010.

BRAY, Cristiane Toller; LEONARDO, Nilza Sanchez T. As queixas escolares na compreensão de educadoras de escolas públicas e privadas. Psicologia Escolar e Educacional, Maringá, v. 15, n. 2, p. 251-261, 2011.

CARVALHO, Tatiana Oliveira; MARINHO-ARAUJO, Claisy Maria. Psicologia escolar no Brasil e no Maranhão: percursos históricos e tendências atuais. Psicologia Escolar e Educacional, Maringá, v. 13, n. 1, p. 65-73, 2009. 
CHECCHIA, Ana Karina A.; SOUZA, Marilene Proença R. Queixa escolar e atuação profissional: apontamentos para a formação de psicólogos. In: MEIRA, Maria Eugênia M.; ANTUNES, Maria Aparecida M. (Orgs.). Psicologia escolar: teorias críticas. São Paulo: Casa do Psicólogo. 2003, p. 139-167.

COSMO, Norma Celine; URT, Sonia da Cunha. As contribuições da psicologia da educação para a escola: um estudo da produção científica da ANPED e da ABRAPEE. InterMeio, Campo Grande, v. 15, n. 30, p. 183-201, 2009.

CRUCES, Alacir V. Valle. Desafios e perspectivas para a psicologia escolar com a implantação das diretrizes curriculares. In: MARINHO-ARAÚJO, Claisy Maria (Org.). Psicologia escolar: novos cenários e contextos de pesquisa, formação e prática. Campinas: Alínea. 2009. p.15-34.

FACCI, Marilda; TESSARO, Nilza; LEAL, Záira Rezende G.; SILVA, Valéria; ROMA, Cintia. Psicologia histórico-cultural e avaliação psicológica: o processo ensino aprendizagem em questão. Psicologia Escolar e Educacional, Maringá, v. 11, n. 2, p. 323-338, 2007.

FACCI, Marilda; EIDT, Nadia Mara. Formação do psicólogo para atuar na instituição de ensino: a queixa escolar em questão. In: AZZI, Roberta Gurgel; GIANFALDONI, Mônica Helena (Orgs.). Psicologia e educação. São Paulo: Casa do Psicólogo. 2011. p. 129-155.

FONTES, Diana Campos; LIMA, Vanessa Aparecida A. A escola segundo alunos do ensino médio de Porto Velho. Psicologia Escolar e Educacional, Maringá, v. 15, n. 1, p. 71-79, 2011.

GASPAR, Fernanda Drummond R.; COSTA, Thaís Almeida. Afetividade e atuação do psicólogo escolar. Psicologia Escolar e Educacional, Maringá, v. 15, n. 1, p. 121-129, 2011.

GUZZO, Raquel Souza Lobo. Desafios cotidianos em contextos educativos: a difícil formação de psicólogos para a realidade brasileira. In: AZZI, Roberta Gurgel; GIANFALDONI, Mônica Helena (Orgs.). Psicologia e educação. São Paulo: Casa do Psicólogo. 2011. p. 253-284.

GUZZO, Raquel Souza Lobo; MEZZALIRA, Adinete S. C. 2008 - Ano da educação para os psicólogos: encaminhamentos e próximos passos In: GUZZO, Raquel Souza Lobo; MARINHO-ARAÚJO, Claisy Maria (Orgs.). Psicologia escolar: identificando e superando barreiras. Campinas: Alínea. 2011. p. 11-32.

GUZZO, Raquel Souza Lobo; et al. Psicologia e educação no Brasil: uma visão da história e possibilidades nessa relação. Psicologia: Teoria e Pesquisa. Campinas, v. 26, n. especial, p. 131-141, 2010.

LESSA, Patrícia Vaz; FACCI, Marilda Gonçalves. A atuação do psicólogo no ensino público do estado do Paraná. Psicologia Escolar e Educacional, Maringá, v. 15, n. 1, p. 131-141, 2011.

LONGAREZI, Andréa Maturano; ALVES, Tamarisa Camargo. A psicologia como abordagem formativa: um estudo sobre formação de professores. Psicologia Escolar e Educacional, Maringá, v. 13, n. 1, p. 125-132, 2009.

MALUF, Maria. Regina. Psicologia escolar: novos olhares e o desafio das práticas. In: MARINHO-ARAÚJO, Claisy Maria (Org.). Psicologia escolar: novos cenários e contextos de pesquisa, prática e formação. 3. ed. Campinas: Alínea, 2010. p. 135-146.

MARINHO-ARAÚJO, Claisy Maria. Psicologia escolar: pesquisa e intervenção. Em Aberto, Brasília, v. 23, n. 83, p. 17-35, 2010.

MARINHO-ARAÚJO, Claisy Maria. A psicologia escolar na nas diretrizes curriculares: espaços criados, desafios instalados In: CAMPOS, Herculano Ricardo. (Org.). Formação em psicologia escolar: realidades e perspectivas. Campinas: Alínea. 2007. p. 17-48.

MARTINEZ, Albertina Mitjáns. 0 que pode fazer o psicólogo na escola? Em Aberto, Brasília, v. 23, n. 83, p. 39-56, 2010.

MEDEIROS, Lucilaide Galdino; BRAZ AQUINO, Fabíola de Sousa. Atuação do psicólogo escolar na rede pública de ensino: concepções e práticas. Psicologia Argumento, Curitiba, v. 29, n. 65, 227-236, 2011.

MEIRA, Maria Eugênia M. Construindo uma concepção crítica de psicologia escolar: contribuições da pedagogia histórico-crítica e da psicologia sócio-histórica. In: MEIRA, Maria Eugênia M.; ANTUNES, Mitsuko Aparecida M. (Orgs.). Psicologia escolar: teorias críticas. São Paulo: Casa do Psicólogo. 2003, p. 13-78. 
MEIRA, Maria Eugênia M. Incluir para continuar excluindo: a produção da exclusão na educação brasileira à luz da psicologia histórico-cultural. In: FACCI, Marilda Gonçalves.; MEIRA, Maria Eugênia M.; TULESKI, Silvana Calvo (Orgs.). A exclusão dos "incluídos": uma crítica da psicologia da educação à patologização e medicalização dos processos educativos. Maringá: Eduem. 2012, p. 75-106.

MEIRA, Maria Eugênia M.; ANTUNES, Mitsuko Aparecida M. Apresentação. In: MEIRA, Maria Eugênia M.; ANTUNES, Mitsuko Aparecida M. (Orgs.). Psicologia escolar: teorias críticas. São Paulo: Casa do Psicólogo. 2003. p. 7-12.

NOVAES, Maria Helena. Repensando a formação e o exercício profissional do psicólogo escolar na sociedade pós-moderna. In: ALMEIDA, Sandra Francesca C. (Org.). Psicologia Escolar: ética e competência na formação e atuação profissional. 3. ed. Campinas: Alínea, 2010. p. 127-134.

OLIVEIRA, Cynthia. B. Evangelista.; MARINHO-ARAÚJO, Claisy Maria. Psicologia escolar: cenários atuais. Estudos e Pesquisa em Psicologia, Rio de Janeiro, ano 9, n. 3, p. 648-663, 2009.

OLIVEIRA, Katya Luciane et al. Produção científica de 10 anos da revista Psicologia Escolar e Educacional (1996/2005). Psicologia Escolar e Educacional, Maringá, v. 10, n. 2, p. 283-292, 2006.

OLIVEIRA, Katya Luciane. et al. Produção científica em avaliação psicológica no contexto escolar. Psicologia Escolar e Educacional, v. 11, n. 2, p. 239-251, 2007.

OVEJERO, Anastasio. Aprendizaje cooperativo: uma eficaz aportacion de la psicologia social a la escuela del siglo XXI. Psicothema, Oviedo, Espanha, v. 5, n. 5, p. 373-391, 1993.

OVEJERO, Anastasio. Psicologia social de la educación. In: ALVARO, José Luis, GARRIDO, Alicia; TORREGROSA, José Ramón (Orgs.). Psicologia social aplicada. Madrid: McGraw-Hill: Interamericana de España, 1996. p. 317-349.

PATTO, Maria Helena S. 0 papel social e a formação do psicólogo: contribuições de um debate necessário. In: PATTO, Maria Helena S. (Org.). Introdução à psicologia escolar. 3. ed. São Paulo: Casa do Psicólogo, 1997. p. 459-475.

PIOTTO, Débora Cristina; ALVES, Renata Oliveira. Estudantes das camadas populares no ensino superior público: qual a contribuição da escola? Psicologia Escolar e Educacional, Maringá, v. 15, n. 1, p. 81-89, 2011.

SANT'ANA, Izabella Mendes et al. Psicólogo e escola: a compreensão de estudantes do ensino fundamental sobre esta relação. Psicologia Escolar e Educacional, Maringá, v. 13, n. 1, p. 29-36, 2009.

SCHLINDWEIN, Luciane Maria. A relação teoria e prática na psicologia da educação: implicações na formação do educador. Psicologia Escolar e Educacional, Maringá, v. 14, n. 2, p. 341-347, 2010.

SOARES, Polliana Galvão; MARINHO-ARAÚJO, Claisy Maria. Práticas emergentes em psicologia escolar: a mediação no desenvolvimento de competências dos educadores sociais. Psicologia Escolar e Educacional, Maringá, v. 14, n. 1, p. 45-54, 2010.

SOUZA, Cláudia Silva; RIBEIRO, Maria José; SILVA, Silvia Maria C. A atuação do psicólogo escolar na rede particular de ensino. Psicologia Escolar e Educacional, Maringá, v. 15, n. 1, p. 53-61, 2011.

SOUSA, Marilene Proença R; SILVA, Silvia Maria C. A atuação do psicólogo na rede pública de educação frente à demanda escolar. In: MARINHO-ARAÚJO, C. M. (Org.). Psicologia escolar: novos cenários e contextos de pesquisa, prática e formação. Campinas: Alínea, 2009. p. 75-105.

SOUZA FILHO, Marcilio Lira; BELO, Raquel; GOUVEIA, Valdiney V. Testes psicológicos: análise da produção científica brasileira no período 2000-2004. Psicologia, Ciência e Profissão, Brasília, v. 26, n. 3, p. 478-489, 2006.

TADA, Iracema Neno C.; SÁPIA, luna Pereira; LIMA, Vanessa Aparecida A. Psicologia escolar em Rondônia: formação e práticas. Psicologia Escolar e Educacional, Maringá, v. 14, n.2, p. 333-340, 2010.

TONDIN, Celso Francisco; DEDONATT, Débora; BONAMIGO, Irme Salete. Psicologia escolar na rede pública de educação dos municípios de Santa Catarina. Psicologia Escolar e Educacional, Maringá, v. 14, n. 1, p. 65-72, 2010. 
VYGOTSKY, Lev S. El problema de la idade. In: VYGOTSKY, Lev S. Obras escogidas. Tomo IV. Madri: Apendizaje Visor, 1996. p. 251-273. Trabalho originalmente publicado em 1932.

VYGOTSKY, Lev S. A Formação social da mente. 7. ed. São Paulo: Martins Fontes, 2007. Trabalho originalmente publicado em 1984.

WANDERER, Aline; PEDROZA, Regina Lúcia S. Elaboração de projetos político-pedagógicos: reflexões acerca da atuação do psicólogo na escola. Psicologia Escolar e Educacional, Maringá, v. 14, n. 1, p. 121-129, 2010.

WITTER, Geraldina P. Pesquisa em psicologia escolar no Brasil. In: WECHSLER, Solange. Múglia. (Org.). Psicologia escolar: pesquisa, formação e prática. 3. ed. Campinas: Alínea, 2008. p. 39-60.

Recebido em:18.06.2013

Aprovado em: 11.12.2013

Laísy de Lima Nunes é doutoranda do Programa de Pós-graduação em Psicologia Social da Universidade Federal da Paraíba.

Simone Salviano Alves é doutoranda do Programa de Pós-graduação em Psicologia Social da Universidade Federal da Paraíba.

Jaqueline Vilar Ramalho é doutoranda do Programa de Pós-graduação em Psicologia Social da UFPB.

Fabíola de Sousa Braz Aquino é professora adjunta do Departamento de Psicologia e do Programa de Pós-graduação em Psicologia Social da UFPB. 